\title{
Apple pomace silage ethanol intake and its effect on sheep
}

\author{
S I slam ${ }^{* 1,2}$, MN I slam², M Matsuzaki ${ }^{2,3}$
}

\begin{abstract}
${ }^{1}$ Faculty of Veterinary Medicine and Animal Science, Bangabandhu Sheikh Mujibur Rahman Agricultural University, Salna, Gazipur 1706, Bangladesh; ${ }^{2}$ The United Graduate School of Agricultural Sciences, I wate University, 3-18-8 Ueda, Morioka 020-8550, I wate, Japan; ${ }^{3}$ Faculty of Agriculture and Life Sciences, Hirosaki University, 3 Bunkyo-cho, Hirosaki 036-8561, Aomori, Japan
\end{abstract}

\begin{abstract}
Two experiments were undertaken to investigate the feeding effect of alcoholic apple pomace silages (APSs) on performance traits, ruminal $\mathrm{pH}$ and blood variables in sheep. In experiment 1, four ewes were fed alfalfa hay cube and either APS (ethanol content was $33.4 \mathrm{~g} / \mathrm{kg} \mathrm{DM}$ ) or concentrate (control) at a ratio of 30:70 of TDN requirement for maintenance and daily $100 \mathrm{~g}$ gain in a $2 \times 2$ crossover design over two 35-day periods. Total body weight gain was higher in control treatment. No significant treatment effect was observed for TDN intake and ruminal $\mathrm{pH}$. Plasma concentrations of ethanol, lactate and $\beta$ hydroxybutyrate (BHBA) were increased after feeding APS. Plasma insulin, glucose, glutamate oxaloacetate transaminase (GOT) and glutamate pyruvate transaminase (GPT) were not significantly differ between the treatments. The area upper or under curves (AUCs) of plasma ethanol and BHBA were greater and lactate was tended to greater in APS treatment. In experiment 2, low and high ethanol contained APSs (L-APS, 44.1g and H-APS, $66.9 \mathrm{~g}$ of ethanol/kg DM) were compared in the same design (Experiment 1). No significant treatment effect was observed for body weight gain and TDN intake. Prefeeding ruminal $\mathrm{pH}$ was lower in L-APS treatment. Insulin concentration was slightly higher in L-APS treatment. However, no significant treatment effect was detected for other variables. According to the consistent increase in plasma ethanol, lactate and BHBA, and the plasma AUCs response of ethanol, lactate and BHBA after feeding of alcoholic-fermented APSs, it would be concluded that APS ethanol consumption affect the post prandial blood metabolism as well as influenced the plasma lactate and BHBA concentrations in the blood.
\end{abstract}

Key words: Apple pomace silage, $\beta$-hydroxybutyrate, ethanol, lactate, sheep

Bangladesh Animal Husbandry Association. All rights reserved. Bang. J. Anim. Sci. 2014.43 (3): $224-231$

\section{Introduction}

Efficient utilization of nutritionally rich agro industrial by-products is a major issue throughout the world because of economic and environmental concerns. Apple pomace (AP) is an agro-industrial by-product which could be used for ruminant feedstuff (Alibes et al. 1984; Gasa et al. 1992). Approximately, 160,000 tons of apple pomacee (AP) is generated annually in Japan (Takahashi and Mori 2006). The storage of this by-product is difficult due to its high moisture content which is above $700 \mathrm{~g} / \mathrm{kg}$ (kennedy et al. 1999). Ensiling could be one method of preserving $\mathrm{AP}$ and it blended with other ingredients to improve nutritional balance of AP (Islam et al. 2014). Ethanol is a normal constituent in silages at various concentrations, depending on the fermentation pattern (Raun and Kristensen 2010). Moreover, ensiling of apple pomace results in the conversion of most of the water-soluble carbohydrates into fermentation end-products (McDonald et al. 1991). Ethanol is the main fermentation end-product in apple pomace silages (Alibes et al. 1984). Ethanol contents of several silages have been reported to be $12-15 \mathrm{~g} / \mathrm{kg}$ DM for corn silages (McDonald et al. 1991; Raun and Kristensen, 2010), 8 - 14 $\mathrm{g} / \mathrm{kg}$ DM for grass silages (Lawrence et al. 2011), 10 - $23 \mathrm{~g} / \mathrm{kg}$ DMfor ensiled TMR silages (Cummins et al. 2009), $54 \mathrm{~g} / \mathrm{kg}$ DM for sugarcane silage (Daniel et al. 2013) and 173 $\mathrm{g} / \mathrm{kg}$ DM for APS (Alibes et al. 1984). Therefore, most of the ruminants are adapted to some ethanol intake. For high ethanol content, APS can be used only in limited amounts (Alibes et al. 1984). Excess alcohol intake might result in increased alcohol load into the liver ( $\mathrm{J}$ ean-Blain et al. 1992) and followed by hours of elevated 
peripheral concentrations of alcohol (Kristensen et al. 2007). Dietary alcohols are associated with the changes in ruminal fermentation pattern (Fang, 2009; Raun and Kristensen 2011). BrandMiller et al. (2007) reported that alcoholic beverage consumption lowers postprandial glycemia in human which may be caused by ethanol's actions of suppression of hepatic gluconeogenesis and glucose output. Similarly, Kondo et al. (2011) found that postprandial hypoglycaemiaand Islam et al. (2014) observed the postprandial transient hyperketonemia after apple pomace silage (APS) feeding is due primarily to ingestion of ethanol.Under such conditions of suppressed gluconeogenesis, liver is unable to convert lactate into glucose, the blood lactate concentration goes up which causes acidosis producing those entire unpleasant hang over side effects and may precipitate an abnormally diminished content of glucose in the blood.

From the above findings it was hypothesized that high concentration of ethanol containing apple pomace silage might affect ruminal environment and blood variables in sheep. Therefore, the objectives of this study was to investigate the feeding effect of different doses alcoholic APSs on performance trait, ruminal $\mathrm{pH}$ and blood variables in sheep.

\section{Materials and Methods}

All procedures involving animals in this study were approved by the Institutional Animal Care and Use Committee at Hirosaki University (A08023).Two experiments were performed using crossover design over two 28-day periods and initial 7 days for dietary adaptation. Four sound and healthy Suffolk shorn ewes, aged 7 months on average, weighing $39 \pm 4 \mathrm{~kg}$ were used at the beginning of the 1st experiment. After taking a certain period of break to avoid summer heat, using the same 4 ewes, aged 14 months on average, weighing $60.3 \pm 3.8 \mathrm{~kg}$ used at the beginning of the 2 nd experiment. In experiment 1 , sheep were allocated to two dietary treatments; alfalfa hay cube and either a commercial concentrate (CP $15.5 \%$ and TDN $70 \%$; control) or APS at a ratio of $30: 70$ on TDN basis. During the first period two sheep were fed on control diet and then fed on APS diet during the second period. The other two ewes received the treatment diets in reverse order. Daily allowance was offered as TDN requirement for maintenance and daily $100 \mathrm{~g}$ gain (Ministry of Agriculture, Forestry and Fisheries, 1996) at 10:00 and 18:00 in 2 equal meals. Ewes were weighed on the each week intervals. The required amount was adjusted weekly based on their BW. Ewes were housed in individual stalls. Trace mineralized salt and water were offered access to at all times. The second experiment was conducted to compare the feeding effects of low ethanol containing APS (L-APS) on blood parameters with that of high ethanol containing APS (H-APS) using the same 4 ewes. Two dietary treatments were feeding of alfalfa hay cube and either L-APS or H-APS at a ratio of 30:70 on TDN basis. The experimental design, feeding rate and management system was identical with that in the experiment 1 .

Fresh AP was obtained from an apple juice factory of the Farm village industry federation of Aomori prefectural agricultural cooperatives at Hirosaki, Japan.

The $65 \% \mathrm{AP}, 2.5 \%$ soybean meal, $17 \%$ wheat bran, $13 \%$ corn and $2.5 \%$ rice straw (as FM basis) were mixed for APS preparation to balance TDN content similar to a commercial concentrate. The L-APS and H-APS were prepared with $70 \%$ AP, $6 \%$ soybean meal, $12 \%$ wheat bran and $12 \%$ beet pulp (as FM basis) at an identical ingredient composition which was formulated to have similar nutrient contents to the concentrate. Because remaining sugars in fresh AP is fermented rapidly and efficiently into ethanol under solid-state fermentation condition (Hang et al. 1981), fresh AP was stored alone in an anaerobic condition for 2 months to secure higher ethanol content before ensiling H-APS. For ensiling APS and L-APS, fresh AP within 2 days of production was used. The AP and all other ingredients were mixed thoroughly by a mechanical mixer and stuffed into plastic container, pressed sufficient to fill properly, topped with air-tight cover and ensiled for at least 2 months before use in the feeding experiments.

Samples were collected during the each period of the each experiment. All samples were dried by forced-air oven at $60{ }^{\circ} \mathrm{C}$ for $48 \mathrm{~h}$ and placed at room temperature for 2 days. Then air dried 


\section{Feeding effect of silage ethanol in sheep}

samples were weighed and milled through a $1 \mathrm{~mm}$ screen and kept into plastic airtight container and stored until further analysis. For AP and APS samples, $100 \mathrm{~g}$ sample with $300 \mathrm{~g}$ distilled water was stored at $4{ }^{\circ} \mathrm{C}$ for overnight and extract the aqueous sample by 4 layer gauze cloth and filter paper. The $\mathrm{pH}$ was measured by using a digital $\mathrm{pH}$ meter (KR5E, AS-PRO, Japan). The moisture content was determined by Toluene Distillation method. The ammonia $\mathrm{N}$ was determined as described by Conway (1962). Ethanol was determined by a specific gravity meter (DA-310, Kyoto Electronics, Japan) after direct distillation of the extracted sample and organic acids were analyzed by a bromotymol blue post-column method using HPLC (D-2000 HSM, Hitachi, Japan). Dry matter (DM), crude protein (CP), ether extract (EE), crude ash and crude fiber (CF) contents were determined according to the methods of AOAC (1990). Neutral detergent fiber (NDF) and acid detergent fiber (ADF) were determined according to the procedures of Van Soest et al. (1991). The $\mathrm{pH}$ value, moisture content and others fermentation profiles of AP and APSs are presented in Table 1. Chemical compositions of experimental feeds are presented in Table 2.

Table 1. The $\mathrm{pH}$ value, moisture content and others fermentation profiles of apple pomace and apple pomace silage

\begin{tabular}{|c|c|c|c|c|c|}
\hline Items & $\begin{array}{c}\text { Fresh } \\
\mathrm{AP}^{1}\end{array}$ & $\begin{array}{c}\text { Fermented } \\
\mathrm{AP}^{2}\end{array}$ & APS & L-APS & H-APS \\
\hline $\mathrm{pH}$ & 4.01 & 4.08 & 3.6 & 3.86 & 3.75 \\
\hline $\begin{array}{l}\text { Moisture } \\
\text { (g kg-1 DM) }\end{array}$ & 767.0 & 856.9 & 593.0 & 630.1 & 661.7 \\
\hline \multicolumn{6}{|c|}{ Organic acids and ethanol ( $g \mathrm{~kg}-\underline{-1} \mathrm{DM})$} \\
\hline Lactic acid & 15.3 & 72.9 & 72.6 & 30.7 & 37.1 \\
\hline Acetic acid & 0.5 & 4.06 & 32.4 & 13.4 & 17.9 \\
\hline Propionic acid & ND & ND & ND & ND & ND \\
\hline Butyric acid & ND & ND & ND & ND & ND \\
\hline Iso-butyric acid & 0.9 & ND & ND & ND & ND \\
\hline VBN in TN & 0.06 & 0.13 & 0.12 & 0.78 & 1.23 \\
\hline Ethanol & 1.3 & 242.5 & 33.4 & 44.1 & 66.9 \\
\hline
\end{tabular}

${ }^{1}$ Fresh apple pomace within 2 days of production; ${ }^{2}$ Fermented $A P$ was stored fresh AP for 2 months in an anaerobic condition; $A P$, apple pomace; APS, apple pomace silage; L-APS, low ethanol containing apple pomace silage; H-APS, high ethanol containing apple pomace silage; DM, dry matter; ND, not detectable; VBN, volatile basic nitrogen; $T N$, total nitrogen
Table 2. Chemical composition of experimental feeds

\begin{tabular}{|c|c|c|c|c|c|c|}
\hline \multirow{4}{*}{ Items } & \multicolumn{3}{|c|}{ Exp-1 } & \multicolumn{3}{|c|}{ Exp-2 } \\
\hline & Alfalfa & & & Alfalfa & & \\
\hline & hay & Concentrate & APS & hay & L-APS & H-APS \\
\hline & cube & & & cube & & \\
\hline \multirow{2}{*}{ Dry matter (\%) } & 91.5 & 88.2 & 40.0 & 91.9 & 37.3 & 33.3 \\
\hline & \pm 1.9 & \pm 0.1 & \pm 0.2 & \pm 0.4 & \pm 0.2 & \pm 2.1 \\
\hline \multicolumn{7}{|c|}{ Composition ( $\left.\mathrm{g} \mathrm{kg}^{-1} \mathrm{DM}\right)$} \\
\hline \multirow{2}{*}{ Organic matter } & 87.7 & 93.2 & 95.7 & 87.5 & 94.5 & 94.1 \\
\hline & \pm 0.6 & \pm 0.2 & \pm 0.2 & \pm 0.5 & \pm 0.0 & \pm 0.1 \\
\hline \multirow{2}{*}{ Crude protein } & 17.7 & 17.1 & 14.4 & 17.7 & 17.2 & 18.6 \\
\hline & \pm 0.4 & \pm 0.3 & \pm 0.4 & \pm 0.2 & \pm 0.5 & \pm 0.6 \\
\hline \multirow{2}{*}{ Ether extract } & 2.0 & 3.2 & 5.5 & 2.0 & 3.2 & 3.8 \\
\hline & \pm 0.1 & \pm 0.02 & \pm 0.02 & \pm 0.1 & \pm 0.1 & \pm 0.1 \\
\hline \multirow{2}{*}{ Crude ash } & 12.3 & 6.8 & 4.4 & 12.5 & 5.5 & 5.9 \\
\hline & \pm 0.4 & \pm 0.2 & \pm 0.1 & \pm 0.2 & \pm 0.1 & \pm 0.2 \\
\hline \multirow{2}{*}{ ADF } & 31.9 & 3.6 & 13.2 & 30.7 & 19.9 & 19.5 \\
\hline & \pm 0.2 & \pm 0.1 & \pm 0.5 & \pm 1.4 & \pm 0.5 & \pm 0.5 \\
\hline \multirow{2}{*}{ NDF } & 44.6 & 20.7 & 34.7 & 43.4 & 35.8 & 37.6 \\
\hline & \pm 0.8 & \pm 0.5 & \pm 1.4 & \pm 1.3 & \pm 1.2 & \pm 0.3 \\
\hline \multirow{2}{*}{ Hemicellulose } & 12.7 & 17.1 & 21.6 & 12.7 & 15.9 & 18.1 \\
\hline & \pm 0.4 & \pm 0.04 & \pm 0.8 & \pm 1.3 & \pm 1.7 & \pm 0.1 \\
\hline \multirow{2}{*}{$\mathrm{NFC}^{1}$} & 31.6 & 56.7 & 52.1 & 31.4 & 48.4 & 48.2 \\
\hline & \pm 0.1 & \pm 0.3 & \pm 1.8 & \pm 0.4 & \pm 2.1 & \pm 0.6 \\
\hline
\end{tabular}

${ }^{1} N F C=(100-C P-E E-N D F-A s h) ; A P S$, apple pomace silage; LAPS, low ethanol containing apple pomace silage; H-APS, high ethanol containing apple pomace silage; ADF: acid detergent fiber, NDF: neutral detergent fiber

On the last day of each 35 day period, series of blood samples were obtained by jugular venipuncture at pre-feeding $(0)$ and at $0.5,1,2$, 4 and 8 hours after the morning feed. The blood was collected into two $7 \mathrm{~mL}$ evacuated tubes containing sodium heparin as an anticoagulant, chilled on ice and centrifuged $(3000 \times \mathrm{g}$ for 15 min at $4{ }^{\circ} \mathrm{C}$ ) to harvest plasma sample. Plasma was aliquotted and stored at $-30{ }^{\circ} \mathrm{C}$ until analyzed for ethanol, lactate, $\beta$-hydroxybutyrate (BHBA), insulin and glucose. Another plasma aliquot was stored at $-80{ }^{\circ} \mathrm{C}$ until analysed for the ethanol-induced liver injury biochemical marker of glutamate oxaloacetate transaminase (GOT) and glutamate pyruvate transaminase (GPT). Plasma ethanol concentration was measured by UV method using an enzymatic F-kit ethanol kit (R-biopharma, Germany). Plasma lactate and BHBA were determined with enzymatic colorimetric methods using medical test instruments, Lactate Pro 2 (Arkray, Japan) 
and PrecisionXceed Pro (Abbott, Japan), respectively. Plasma insulin concentration was assayed by a sandwich ELISA technique with Mercodia ovine insulin ELISA kit (Mercodia, Sweden). Plasma glucose was determined with an enzymatic colorimetric method using Glucose ClItest Wako (Wako pure Chemicals, Japan). Plasma GOT and GPT activities were also determined with the enzymatic colorimetric method using GOT.GPT Cll-test Wako (Wako pure Chemicals, Japan). The area upper or under the curve (AUC) for 8 hours after feeding of plasma parameters was calculated as an indicative of the responses to feeding in each variables.

Hemicellulose was calculated as the difference between the NDF and ADF. Non-fibrous carbohydrate (NFC) was calculated by using the equation of NRC (2001): NFC $=(100-C P-E E-$ NDF - Ash). The mean BW (MBW) of each animal was calculated as the average of the initial and end of the BW. Total body weight gain (TBWG) and total TDN intake (TDNI) were calculated for each experimental period. Ethanol intake was calculated from APSs intake and ethanol contents of the APSs.

Ruminal fluid samples were obtained from each animal on 28d of each period for both experiments. Rumen fluid was collected prefeeding (0) and 2 hours after the morning feed using a transesophageal sampler (Toyox.Co.JP). Ruminal fluid $\mathrm{pH}$ was measured immediately after collection using a digital $\mathrm{pH}$ meter (AS-PRO KR5E).
All data were analyzed using the general linear model (GLM) procedure of SAS (2003). Sheep, period and treatment were included in the model. Treatment means were separated using a PDIFF option, protected by overall F-test. Difference was considered statistically significant at $p<0.05$.

\section{Results}

No health problems were observed in any of ewes throughout the experiments 1 and 2. LS means for performance traits of the ewes are presented in Table 3. In experiment 1, no difference was detected in MBW between the treatments. However, the total BWG was lower $(p<0.05)$ in the APS than control group. Total TDN intake and TDN intake for metabolic BW did not differ between the treatments. Ewes on APS treatment received an average of $494.05 \mathrm{mmol} / \mathrm{d}$ of ethanol whereas ewes on control were assumed to receive any of alcohol. In experiment 2, no significant differences were observed in MBW, total BWG, total TDNI and TDN intake for metabolic BW; although ethanol intake was significantly greater $(p<0.01)$ in the ewes fed on $\mathrm{H}$-APS than L-APS treatment.

LS means for ruminal $\mathrm{pH}$ of the ewes are presented in Table 3. In experiment 1, prefeeding and post-feeding ruminal $\mathrm{pH}$ did not differ between the treatments. In experiment 2, prefeeding ruminal $\mathrm{pH}$ was lower $(p<0.05)$ in the LAPS than H-APS group. However, post-feeding ruminal $\mathrm{pH}$ did not differ between the treatments.

Table 3. Performance traits and ruminal $\mathrm{pH}$ in the ewes ${ }^{1}$

\begin{tabular}{lcccccccc}
\hline Items & Control & APS & SE & p-value & L-APS & H-APS & SE & p-value \\
\hline Performance traits & & & & & & & & \\
MBW, kg & 41.43 & 41.43 & 4.50 & 1.0 & 60.2 & 60.3 & 2.78 & 0.96 \\
TBWG, kg & 5.33 & 4.88 & 0.06 & 0.04 & 5.08 & 4.66 & 0.19 & 0.27 \\
Total TDNI, kg & 22.73 & 22.55 & 0.18 & 0.56 & 30.60 & 30.14 & 0.39 & 0.48 \\
TDNI (g/kg W0.75/d), kg & 49.74 & 49.41 & 0.08 & 0.1 & 50.54 & 49.83 & 0.45 & 0.38 \\
Ethanol Intake2 (mmol/d) & $\mathrm{ND}$ & 494.05 & 0.56 & 0.0001 & 804.46 & 1087.73 & 15.84 & 0.008 \\
Ruminal pH & & & & & & & & \\
Pre-feeding (0 hour) & 6.84 & 7.26 & 0.18 & 0.24 & 6.98 & 7.18 & 0.03 & 0.04 \\
Post feeding (2 hours) & 6.72 & 6.95 & 1.18 & 0.48 & 6.54 & 6.40 & 0.18 & 0.65 \\
\hline
\end{tabular}

${ }^{1}$ Values are LS means of four ewes per treatment; '2Ethanol intake was calculated from APSs intake and ethanol contents of the APSs; APS, apple pomace silage; L-APS, low ethanol containing apple pomace silage; H-APS, high ethanol containing apple pomace silage; SE, standard error of the mean; MBW, mean body weight; TBWG, total body weight gain; TDNI, total digestible nutrient intake; ND, not detectable 
Table 4. Blood variables in the ewes ${ }^{1}$

\begin{tabular}{lcccccc}
\hline Items & Control & APS & $\begin{array}{c}\mathrm{p}- \\
\text { value }\end{array}$ & $\begin{array}{c}\mathrm{L}- \\
\text { APS }\end{array}$ & $\begin{array}{c}\mathrm{H}- \\
\text { APS }\end{array}$ & $\begin{array}{c}\mathrm{p}- \\
\text { value }\end{array}$ \\
\hline Ethanol $(\mathrm{mmol} / \mathrm{L})$ & 0.15 & 1.77 & 0.04 & 2.02 & 1.82 & 0.71 \\
Lactate $(\mathrm{mmol} / \mathrm{L})$ & 1.83 & 3.82 & 0.08 & 2.64 & 2.75 & 0.83 \\
BHBA(mmol/L) & 0.71 & 1.15 & 0.06 & 1.5 & 1.43 & 0.42 \\
Glucose $(\mathrm{mg} / \mathrm{dL})$ & 78.84 & 76.09 & 0.59 & 58.58 & 59.00 & 0.86 \\
Insulin $(\mu \mathrm{g} / \mathrm{L})$ & 0.55 & 0.77 & 0.16 & 0.91 & 0.77 & 0.02 \\
GOT $(\mathrm{IU} / \mathrm{L})$ & 49.31 & 55.99 & 0.29 & 65.93 & 64.80 & 0.91 \\
GPT(IU/L) & 5.07 & 7.08 & 0.28 & 3.36 & 3.19 & 0.40 \\
\hline
\end{tabular}

${ }^{1}$ Values are LS means of four ewes per treatment; APS, apple pomace silage; L-APS, low ethanol containing apple pomace silage; $H$-APS, high ethanol containing apple pomace silage; BHBA, $\beta$ hydroxybutyrate; GOT, glutamate oxaloacetate transaminase; GPT, glutamate pyruvate transaminase

The AUC of plasma variablesfor 8 hours sampling windowsin experiment 1 are represented in Figure 1. The AUC of plasma ethanol inAPS treatment was greater $(p<0.05)$ than the control. The AUC of plasma lactate was tended to grater ( $p=0.08)$ in APS treatment than control. The AUC of plasma BHBA in the APS treatment was also greater $(p<0.05)$ than the control treatment. No significant differences were observed between the APS and control treatments for the AUCs of plasma insulin, glucose, GOT and GPT. The AUC of plasma variablesfor 8 hours sampling windowsin experiment 2 are represented in Figure 2. No significant differences were observed between the L-APS and H-APS treatments for the AUCs of plasma ethanol, lactate, BHBA, glucose, insulin, GOT and GPT.
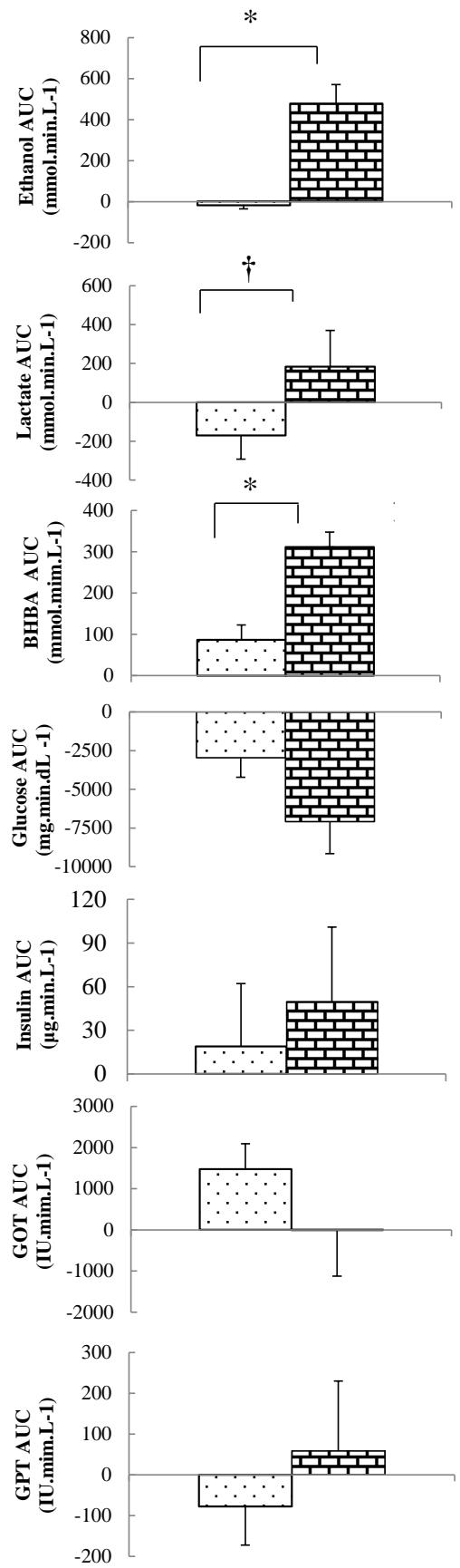

Figure 1. The area upper or under the curve (AUC) of plasma ethanol, lactate, $\beta$-hydroxybutyrate (BHBA), glucose, Insulin, glutamate oxaloacetate transaminase (GOT) and glutamate pyruvate transaminase (GPT)of ewes fed on control treatment (dotted bar) or APS treatment (brick bar) for 8 hours sampling windows. Each data point is the mean of 4 observations \pm standard error of the means. The dagger or asterisk indicate a tendency toward significant difference between treatments $(\dagger, p<0.1$ and *, $p<0.05)$. 

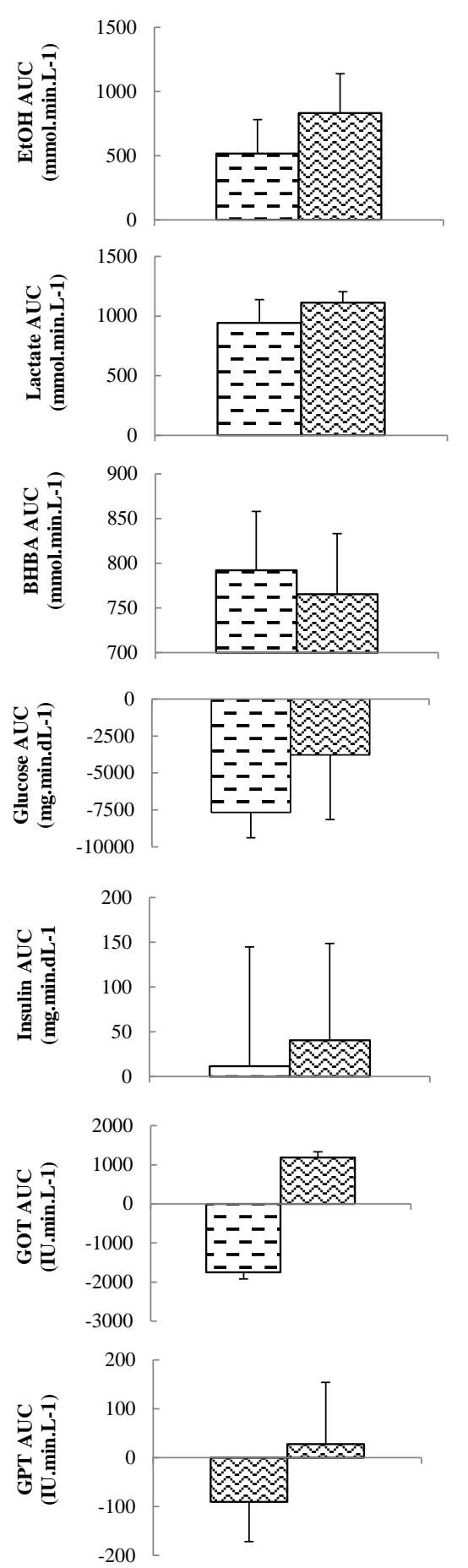

Figure 2. The area upper or under the curve (AUC) of plasma ethanol, lactate, $\beta$-hydroxybutyrate (BHBA), glucose, Insulin, glutamate oxaloacetate transaminase (GOT) and glutamate pyruvate transaminase (GPT)of ewes fed on control treatment (dashed bar) or APS treatment (zig zag bar) for 8 hours sampling windows. Each data point is the mean of 4 observations \pm standard error of the means

\section{Discussion}

High fermentative sugar (Alibes et al. 1984) and more susceptibility to enzymatic hydrolysis
(Gullón et al. 2007) of AP leads to a rapid production of ethanol and lactic acid because there is enough soluble carbohydrate available for sugar fermentation by the action of lactic acid bacteria and yeast. In fact in the present study, negligible ethanol content was observed in fresh AP and after 2 month of ensiling, fermented APS contained a considerable amount of ethanol which blended with other ingredients to improve nutritional balance of fresh AP. The alcoholic AP was identified as the largest ethanol content $\left(242.5 \mathrm{~g} \mathrm{~kg}^{-1}\right)$ than that of in a single APS (173 g $\mathrm{kg}^{-1}$ ) reported by Alibes et al. (1984).It's indicated that drained fluid of H-APS were particularly rich in alcohol. By using fermented AP for preparation of balanced H-APS, we succeed to increase its ethanol content by $52 \%$ with compared to that of L-APS which indicate that various concentrations of alcohol in silages are depending on the fermentation profile (Kristensen et al. 2010). Ethanol content of APSs used in this experiment were more than 2 to 4 times higher than that of corn silage (McDonald et al. 1991; Raun and Kristensen 2010), 1.5 to 3 times higher than that of grass silage (Lawrence et al. 2011), 2 to 5 times higher than that of ensiled TMR silages (Cummins et al. 2009) and 8-16 times higher ethanol than that of sugarcane silage (Daniel et al. 2013).

Lower CP intake influenced the lower TBWG in the APS group than control group. On the other hand, Taasoli and Kafilzadeh (2008) reported that the improved ADG by feeding of both ensiled and dried AP in finishing lambs. The APS used in the first experiment had lower $\mathrm{CP}$ and higher fiber contents compared to the concentrate mixture. The formulated APS was blended to have similar energy content to the concentrate, but did not further fortified CP content of APS because its estimated $C P$ value was sufficient to meet the requirement of growing ewe lambs (Ministry of Agriculture, Forestry and Fisheries, 1996). However, any of performance traits was not affected by a difference in ethanol intake between L-APS and H-APS treatments in the experiment 2. Therefore, Suffolk sheep are capable to utilize $\sim 1088 \mathrm{mmol} / \mathrm{d}$ ethanol intake from APS without any clinical sign of adverse effect.

The plasma ethanol, lactate and BHBA concentrations were increased after feeding of 


\section{Feeding effect of silage ethanol in sheep}

APS treatment. Islam et al. (2014) reported the similar results after feeding of alcoholic fermented APS and concluded that APS ethanol consumption induce postprandial transient hyperketonemia through suppression of hepatic gluconeogenesis. Raun and Kristensen (2011) also reported that a strong ketogenic shift appeared to happen on glucose metabolism, comparing ethanol treatment with propanol treatment. On the basis of the results of kinetic study of infused ethanol in sheep, Jean-Blain et al. (1992) considered that daily ethanol intake ranging from 0.2 to $1 \mathrm{~g} / \mathrm{kg}$ BW (4.3 to 21.7 $\mathrm{mmol} / \mathrm{kg}$ BW) can be metabolized by rumen microflora and enzymatic system of the host and plasma ethanol level remains below $0.25 \mathrm{~g} / \mathrm{L}(5.4$ $\mathrm{mmol} / \mathrm{L}$ ). These estimates are correspond very well with the findings of present study where the highest ethanol intake of the ewes was 18.04 $\mathrm{mmol} / \mathrm{kg}$ BW and the highest plasma ethanol level was $1.82 \mathrm{mmol} / \mathrm{L}$. Heitmann et al. (1987) suggested that ketosis in pregnant sheep and lactating cows are prevented by BHBA stimulation of pancreatic insulin production, and this may explain increased plasma insulin level in theL-APS treatment. It is established that ethanol ingestion resultant of hypoglycemia (Krebs et al. 1969; Brand-Miller et al. 2007) which decrease in the cytosolic free $\mathrm{NAD}^{+}$to $\mathrm{NADH}$ ratio. This change in the redox state decreases the concentration of pyruvate and other gluconeogenic intermediates (Krebs et al. 1969) and thus cause postprandial hypoglycemia in sheep fed on APS diets (Kondo et al. 2010; 2011). Although we failed to demonstrate significant decrease in plasma glucose concentrations in the APSs treatments, however, increased plasma lactate and BHBA levels should be an indication of suppressed gluconeogenesis. We failed to detect ethanol induce liver injury biomarker GOT and GPT toxic effects and no health problems were also observed during the experimental periods.

According to the consistent increase in plasma ethanol, lactate and BHBA, and the plasma AUCs response of ethanol, lactate and BHBA after feeding of alcoholic-fermented APSs, it would be concluded that APS ethanol consumption affect the postprandial blood metabolism as well as influenced the plasma lactate and BHBA concentrations in the blood.

\section{References}

Alibes X, Muñoz F, Rodriguez J (1984). Feeding value of apple pomace silage for sheep. Animal Feed Science and Technology, 11: 189-197.

AOAC (1990). Association of Official Analytical Chemists, Official Methods of Analysis. $15^{\text {th }}$ Edition. Arlington, VA.

Brand-Miller J C, Fatema K, Middlemiss C, Bare M, Liu V, Atkinson F, Petocz P (2007). Effect of alcoholic beverages on postprandial glycemia and insulinemia in lean, young, healthy adults. The American Journal of Clinical Nutrition, 85: 1545-1551.

Conway EJ (1962). Microdiffusion analysis and volumetric error.5th Edition. Crosby Lockwood, London, 322.

Cummins B, Kiely PO, Keane MG, Kenny DA (2009). Feed intake pattern, behavior, rumen characteristics and blood metabolites of finishing beef steers offered total mixed rations constituted at feeding or ensiling. I rish J ournal of Agricultural and Food Research, 48: 57-73.

Daniel J LP, Weiß K, Custódio L, SáNeto A, Santos MC, Zopollatto M, Nussio LG (2013). Occurrence of volatile organic compounds in sugarcane silages. Animal Feed Science and Technology, 185: 101-105.

Fang J (2009). Effect of ensilage of apple pomace on the nutritive value in sheep. Tohoku Journal of Animal Science and Technology, 59: 1-6.

Gasa J, Castrillo C, Guada JA, Balcells J (1992). Rumen digestion of ensiled apple pomace in sheep: effect of proportion in diet and source of nitrogen supplementation. Animal Feed Science and Technology, 39: 193-207.

Gullón B, Falqué E, Alonso J L, Parajó JC (2007). Evaluation of apple pomace as a raw material for alternative applications in food industries. Food Technology and Biotechnology. 45: 426-433.

Hang YD, Lee CY, Woodams EE, Cooley HJ (1981). Production of alcohol from apple pomace. Applied Environmental Microbiology, 42: 1128- 1129.

Heitmann RN, Dawes DJ, Sensenig SC (1987). Hepatic ketogenesis and peripheral ketone body utilization in the ruminant. Journal of Nutrition, 117: 1174-1180. 
Islam S, Fang J, Suzuki H, Matsuzaki M (2014). Postprandial hyperketonemia after feeding of alcoholic fermented apple pomace silage in Suffolk ewes. Journal of Animal Science Advances, 4: 845-854.

Jean-Blain C, Durix A, Tranchant B (1992). Kinetics of ethanol metabolism in sheep. Reproductive Nutrition Development, 32: 83-90.

Kennedy M, List D, Lu Y, Newman RH, Sims IM, Bain PJS (1999). Apple pomace and products derived from apple pomace: uses, composition and analysis. In: Analysis of Plant Waste Materials, 20: 75-119.

Kondo M, Moriuchi H, Fang J, Suzuki H, Matsuzaki, M (2011). Postprandial hypoglycemia after feeding of alcohol-fermented apple pomace silage (abstract). 2011 ADAS ${ }^{\circledR}$ ASAS join annual meeting abstract; Ruminant Nutrition: Ruminal Metabolism, W390.

Kondo M, Wang F, Kimura A, Ogasawara R, Fang J, Suzuki H, Matsuzaki M (2010). The decrease in blood glucose after feeding of alcohol-fermented apple pomace silage in Suffolk sheep. Japan Journal of Sheep Science, 47: 13-19.

Krebs HA, Freedland RA, Hems R, Stubbs M (1969). Inhibition of hepatic gluconeogenesis by ethanol. Biochemical Journal, 112: 117-124.

Kristensen NB, Storm A, Raun BML, Røjen BA, Harmon DL (2007). Metabolism of silage alcohols in lactating dairy cows. Journal of Dairy Science, 90: 1364-1377.

Kristensen NB, Sloth, KH, Højberg O, Spliid $\mathrm{NH}$, Jensen C, Thøgersen R (2010). Effects of microbial inoculants on corn silage fermentation, microbial contents, aerobic stability, and milk production under field conditions. Journal of Dairy Science, 93: 3764-3774.
Lawrence P, Kenny DA, Earley B, Crews Jr DH, McGee M (2011). Grass silage intake, rumen and blood variables, ultrasonic and body measurements, feeding behaviour and activity in pregnant beef heifers differing in phenotypic residual feed intake. J ournal of Animal Science, 89: 3248-3261.

McDonald P, Henderson N, Heron S (1991). The Biochemistry of Silage.2nd edition. Chalcombe Publications, Bucks, UK.

Ministry of Agriculture, Forestry and Fisheries (1996). Japanese Feeding Standard for Sheep. Tokyo, Japan.

NRC (2001). National Research Council. Nutrient requirement of dairy cattle. 7th edition.

Raun BML, Kristensen NB (2010). Propanol in maize silage at Danish dairy farms. Acta Agriculturae Scandinavica, 60: 53-59.

Raun BML, Kristensen NB (2011). Metabolic effects of feeding ethanol or propanol to postpartum transition Holstein cows. Journal of Dairy Science, 94: 2566-2580.

SAS (2003). SAS/STAT ${ }^{\circledR}$ Software: Changes and enhancements through release. SAS Institute Inc., Version 9.1. Cary, NC, USA.

Taasoli G, Kafilzadeh F (2008). Effects of dried and ensiled apple pomace from puree making on performance of finishing lambs. Pakistan J ournal of Biological Sciences, 11: 294- 297.

Takahashi J, Mori T (2006). Hydrogen Production from reaction of apple pomace with water over commercial steam reforming $\mathrm{Ni}$ catalysts. Journal of Japan Petroleum Institute, 49: 262267.

Van Soest PJ, Robertson JB, Lewis BA (1991). Methods for dietary fiber, Neutral detergent fiber and nonstarch polysaccharides in relation to animal nutrition. Journal of Dairy Science, 74: 3583-3597. 